\title{
Thermoluminescence characteristics and kinetic analysis of beta irradiated $\mathrm{Ca}_{4} \mathrm{LaO}\left(\mathrm{BO}_{3}\right)_{3}$ phosphor
}

\author{
Ziyafer Gizem PORTAKAL UÇAR ${ }^{1, * i D}$ \\ ${ }^{1}$ Çukurova University, Science and Arts Faculty, Physics Department, 01330, Adana/TURKEY
}

\begin{abstract}
Thermoluminescence (TL) properties of synthesized $\mathrm{Ca}_{4} \mathrm{LaO}\left(\mathrm{BO}_{3}\right)_{3}$ exposed to beta radiation were analyzed and TL kinetic parameters of activation energy $E(\mathrm{eV})$, the frequency factor $s$ $\left(\mathrm{s}^{-1}\right)$, and order of kinetics $b$ were determined in this study. TL glow curve recorded in 25-500 ${ }^{\circ} \mathrm{C}$ range presented two TL maxima around 70 and $200{ }^{\circ} \mathrm{C}$ and therefore, thermal cleaning was utilized for the further investigations on a single TL maximum. To investigate dosimetric characterizations of $\mathrm{Ca}_{4} \mathrm{LaO}\left(\mathrm{BO}_{3}\right)_{3}$, additive dose and various heating rates, reusability, and storage time measurements were performed. $\mathrm{Ca}_{4} \mathrm{LaO}\left(\mathrm{BO}_{3}\right)_{3}$ has a linear dose range between 10 to $100 \mathrm{~Gy}$ with a heating rate of $2{ }^{\circ} \mathrm{C} / \mathrm{s}$. An anomalous case of heating rate behavior was attained for the TL measurements carried out using variable heating rates between 0.1 and 10 ${ }^{\circ} \mathrm{C} / \mathrm{s}$ which was considered through the semi-localized transition model. Reusability and storage time measurements indicated the results within the 5\% standard deviation. The kinetic parameters were estimated by the initial rise (IR) and glow curve deconvolution (GCD) methods. Continuously distributed trapping levels were identified by $T_{\mathrm{M}}-T_{\text {stop }}$ with $E$ ranging from 1.25 to $1.45 \mathrm{eV}$. GCD identified that the glow curve expressed general order kinetics and consist of three overlapping traps.
\end{abstract}

\section{Introduction}

The thermoluminescence (TL) process includes the excitation of electrons into the conduction band from the valance band due to an exposure by a radiation source and pursued by their capture by electron traps connected with defects or impurities in the crystal lattice. During the TL readout procedure, the trapped electrons are released by the heating usually through the conduction band and may execute radiative recombination with hole centers in the sample. Produced luminescence is detected as a function of the temperature [1]. TL method is widely used in various fields such as radiation and retrospective dosimetry for personal and environmental monitoring [2]. In general, TL is preferred in the field of radiation dosimetry and dosimetric properties such as reusability, linear dose response, negligible fading, heating rate behavior, i.e. are of great importance. Moreover, various models have been suggested to investigate the kinetic parameters of the traps within the phosphor. The single trap model, localized transition models, and semilocalized transition (SLT) model are the principally employed theoretical models of TL [3]. Mandowski who developed the SLT model reported that the spatially related structure of traps and recombination centers are responsible for various anomalous TL phenomena in his further investigations [4-6]. The displacement peaks, the origination of very high frequency factors (s) connected with the cascade detrapping mechanism, and the anomalous statement of the heating rate are argued by the SLT model [7]. Besides, the important points to understand the dosimetric characteristics of TL materials are the trap parameters of glow peaks providing main information on the TL emission mechanisms [8]. Since TL can provide information on the traps representing the recombination centers of a TL glow curve by the trap parameters of activation energy $E$, frequency factor $s$, and order of kinetics $b$.

Borate compounds have a great interest owing to their good thermal and chemical stability, low cost, convenient storage stability after the irradiation, high sensitivity, comparatively easy preparation, and the use of light-emitting diode lightening applications [9]. Detailed luminescence properties of various borate compounds have been studied for a long time. [9-13].

*Corresponding author. e-mail address: gportakal@cu.edu.tr 
In addition to these investigations, TL studies are of great importance to evaluate the dosimetric characteristics and kinetic parameters of borate compounds. Especially, $\mathrm{Li}_{2} \mathrm{~B}_{4} \mathrm{O}_{7}$ is one of the most preferred borate phosphors by reason of its low effective atomic number $\left(Z_{\text {eff }}=7.3\right)$ to be used in radiation dosimetry [10-12]. However, the development of fresh phosphor materials for radiation detection is one of the primary works in TL dosimetry research. Recently, $\mathrm{Ca}_{4} \mathrm{LaO}\left(\mathrm{BO}_{3}\right)_{3}$ (CLBO) phosphor has been searched in terms of its luminescence properties [14-16] and it is stated that CLBO has colortunable luminescence after doping with rare-earth ions. In addition to these few luminescence studies, CLBO was investigated in terms of its other properties as well. Adams et al. stated the nonlinear optical characteristics of CLBO crystal [17]. Moreover, optical and thermal properties [18] electronic structure [19], magnetic properties [20], growth and spectroscopic properties [21-22], and detailed crystal structure [23] of CLBO were reported. Yet, the previous investigations about CLBO phosphor do not contain a TL study. This feature is the motivation for this work using TL.

The present work reports the TL characterization of beta-irradiated $\mathrm{Ca}_{4} \mathrm{LaO}\left(\mathrm{BO}_{3}\right)_{3}$ prepared by a solid state method. First, the most suitable filter was selected by testing the available filter combinations in the TL reader and all measurements were utilized using the chosen filter. Second, preheating was applied to eliminate the unstable low-temperature TL peak(s) of CLBO phosphor. Dosimetric tests such as dose response, heating rate behaviors, storage time (short time fading), and reusability of CLBO exposed to beta radiation were evaluated after preheating. In addition, TL trapping parameters of a TL peak maximum were conducted using the initial rise (IR) method. The possible locations of the overlapping TL peaks were determined by $T_{\mathrm{M}}-T_{\text {stop }}$ analysis and the trapping parameters of each deconvolved peak were found by the glow curve deconvolution (GCD) method.

\section{Experimental Details}

\subsection{Synthesis and XRD Analysis of $\mathrm{Ca}_{4} \mathrm{LaO}\left(\mathrm{BO}_{3}\right)_{3}$ Phosphor}

High-purity starting materials as $\mathrm{CaCO}_{3}(99.99 \%$, Merck), $\mathrm{La}_{2} \mathrm{O}_{3}$ (99.9\%, Alfa Aesar), and $\mathrm{H}_{3} \mathrm{BO}_{3}$ (99.9\%, Merck) were used to synthesize $\mathrm{Ca}_{4} \mathrm{LaO}\left(\mathrm{BO}_{3}\right)_{3}$ phosphor by standard solid state reaction method. The oxide mixtures (weights on the strength of the stoichiometric ratio of the mixture according to the correct formula below) were ground in an agate mortar and mixed thoroughly.
$4 \mathrm{CaCO}_{3}+1 / 2 \mathrm{La}_{2} \mathrm{O}_{3}+3 \mathrm{H}_{3} \mathrm{BO}_{3} \rightarrow \mathrm{Ca} 4 \mathrm{LaO}\left(\mathrm{BO}_{3}\right)_{3}+$ $9 / 2 \mathrm{H}_{2} \mathrm{O}+4 \mathrm{CO}_{2}$

The powder composition was transferred into a crucible and firstly heated at $900{ }^{\circ} \mathrm{C}$ in the air for $1 \mathrm{~h}$ to affect the decomposition of the boric acid. The powder sample was immediately cooled, reground, and reheated to $1200{ }^{\circ} \mathrm{C}$ for several hours (up to $6 \mathrm{~h}$ ). Finally, the synthesized phosphor was cooled to room temperature (RT) to be used in further investigations. A small amount of the synthesized mixture was reserved for X-ray diffraction (XRD) analysis. The phase composition and crystallinity of synthesized $\mathrm{Ca}_{4} \mathrm{LaO}\left(\mathrm{BO}_{3}\right)_{3}$ phosphor were identified by XRD using Rigaku Miniflex 600 at scanning steps of $0.1^{\circ}$ in the range $10 \leq 2 \theta\left(^{\circ}\right) \leq 80$ with $\mathrm{Cu} \mathrm{Ka}(40 \mathrm{kV}, 15 \mathrm{~mA}$, $\lambda=0.15405 \mathrm{~nm}$ ) radiation.

\subsection{Thermoluminescence (TL) Measurements}

Lexsyg Smart TL/OSL reader having a ${ }^{90} \mathrm{Sr} /{ }^{90} \mathrm{Y}$ beta source with $0.10 \mathrm{~Gy} / \mathrm{s}$ dose rate was used for all the TL measurements. Powder sample weighed as $30 \mathrm{mg}$ was pressed to form the required pellet (diameter and thickness of 6 and $0.75 \mathrm{~mm}$ ) by being held under a pressure of 2 ton-force $/ \mathrm{cm}^{2}$ for 10 minutes. A single aliquot (in $29.8 \mathrm{mg}$ weight) in pellet form was employed in TL characterization and kinetic parameter calculation studies. TL glow curves were achieved from RT to $500{ }^{\circ} \mathrm{C}$ with a linear heating rate of 2 ${ }^{\circ} \mathrm{C} / \mathrm{s}$ (apart from the heating rate analysis). Filter test of CLBO sample irradiated by 10 Gy beta dose was operated using the various filter combinations in the TL reader. Preheating was applied to eliminate the low temperature peak(s) by using the preheat $(\mathrm{PH})$ plateau test to determine both $\mathrm{PH}$ temperature and duration. The preheated CLBO sample was exposed to beta irradiation at additive dose between 0.1 and 150 Gy for dose response evaluation. For investigations related to the impact of heating rate, the pellet sample was irradiated by $10 \mathrm{~Gy}$ beta dose and measured at variable heating rates $\left(0.1-10^{\circ} \mathrm{C} / \mathrm{s}\right)$. Measurements conducted in an $\mathrm{N}_{2}$ environment were made using the net $\mathrm{TL}$ intensity by subtracting the background from the first readout.

\subsection{Kinetic analysis of TL glow curves}

The kinetic analysis and the trap parameters of the CLBO phosphor were investigated from the obtained TL glow curve data by the $T_{\mathrm{M}}-T_{\text {stop }}$, initial rise (IR), and glow curve deconvolution (GCD) methods. 


\subsection{1. $T_{\mathrm{M}}-T_{\text {stop }}$ method}

One method to separate the overlapping TL peaks is based on preheating up to a stopping temperature $\left(T_{\text {stop }}\right)$ before determining the TL glow curve. For this purpose, an irradiated phosphor is heated at a linear heating rate to $T_{\text {stop }}$ related to a location on the low temperature tail of the first glow peak. Then, the sample rapidly cooled to RT is then reheated at the same heating rate to obtain the remaining TL glow curve, and the position of the first maximum temperature $\left(T_{\mathrm{M}}\right)$ is recorded. The process is repeated for newly irradiated sample using various $T_{\text {stop }}$ which are increased by a small increment (i.e. between 2 and $5{ }^{\circ} \mathrm{C}$ ). This method is generally used to estimate the numbers and possible locations of overlapped TL peaks and the so-called $T_{\mathrm{M}}-T_{\text {stop }}$ method. In general, $T_{\mathrm{M}}-T_{\text {stop }}$ plot represents two different manners as "staircase" structure or "continuous line" with a slope of 1.0 [24].

\subsubsection{Initial rise (IR) method}

This method defines that the initial part of the TL glow curves up to $15 \%$ of its peak maximum $\left(I_{\mathrm{M}}\right)$ is an exponential function of the temperature and is reported to be pertinent in all the order of kinetics [25]. Thus, a plot of $\ln (I)$ versus $1 / T$ produces a smooth line with a slope of $-E / \mathrm{k}$ from which the activation energy $E$ is determined where $I$ is the TL intensity and $\mathrm{k}$ is the Boltzmann's constant. Once $E$ is found, the frequency factor $s$ is thereafter computed using the intercept of the line equal to $\ln (s / \beta)$. Here $\beta$ presents the heating rate in a unit of K. In the framework, the IR method was employed to three different glow curves obtained using additive dose, various heating rates, and $T_{\mathrm{M}}-T_{\text {stop }}$ measurements.

\subsubsection{Glow curve deconvolution (GCD) method}

GCD method is used to decompose the TL glow curve and achieve the kinetic parameters of the material. This method is applied in this study to determine the number of TL peaks in the glow curve and to extract the trap parameters $E, s$, and $b$. Figure of merit (FOM) defines the best GCD fitting of theoretical and experimental glow curve and FOM function is calculated using Eq. (1).

$$
F O M=\left|\sum\left(T L_{\text {exp }}-T L_{f i t}\right) / \sum T L_{f i t}\right| x 100
$$

$T L_{\text {exp }}$ defines the measured intensity at variable $T$ in experimental data while $T L_{\text {fit }}$ represents the best-fitted values of the intensity by the GCD method. FOM value states the goodness of fit and the values less than 2.5 $\%$ refer to a good fit [26]. The TL glow curve of CLBO phosphor was decomposed by the tgcd: an R package [27] software.

\section{Results and Discussion}

\subsection{Structural properties}

The crystalline structure of CLBO phosphor was investigated by XRD. As presented in Fig.1, the observed reflection peaks are in good agreement and match well with the calcium lanthanum borate $\left(\mathrm{Ca}_{4} \mathrm{LaO}\left(\mathrm{BO}_{3}\right)_{3}\right)$ belonging to the $C 1 m 1$ (No. 8) space group in the monoclinic crystal system (standard card: PDF\#52-0621).

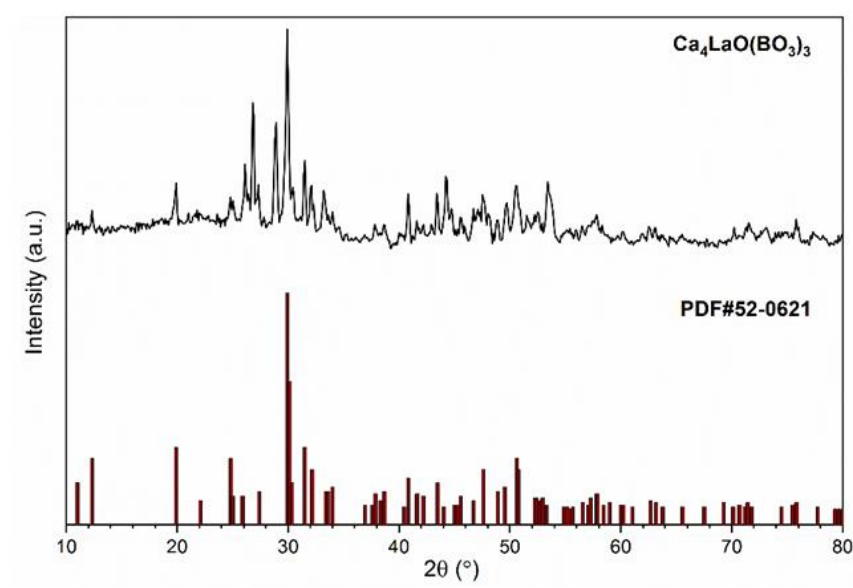

Figure 1. XRD pattern of $\mathrm{Ca}_{4} \mathrm{LaO}\left(\mathrm{BO}_{3}\right)_{3}(\mathrm{CLBO})$ phosphor.

It was observed that the synthesized CLBO phosphor has the cell parameters of $\mathrm{a}(\AA): 8.170, \mathrm{~b}(\AA): 16.082$, $c(\AA): 3.627$ and $\alpha\left(^{\circ}\right): 90, \beta\left(^{\circ}\right): 101.39, \gamma\left({ }^{\circ}\right): 90$. However, three undefined peaks at $\sim 27^{\circ}(222), 29^{\circ}$ (123), and $53^{\circ}(622)$ attract attention. These diffraction peaks are from the starting material of $\mathrm{La}_{2} \mathrm{O}_{3}$ (PDF\#03065-3185). The possible explanation is due to the feature of $\mathrm{La}_{2} \mathrm{O}_{3}$, namely, its aptitude to quickly absorb moisture from the atmosphere up to $20 \%$ of its weight [28]. Therefore, absorbed $\mathrm{H}_{2} \mathrm{O}$ traces might be removed during the heating procedure at $1200{ }^{\circ} \mathrm{C}$ and so $\mathrm{La}_{2} \mathrm{O}_{3}$ may have remained. Nevertheless, the amount of $\mathrm{La}_{2} \mathrm{O}_{3}$ impurity was negligibly low and it is not thought to affect the TL characterization results.

\section{2. $\mathrm{TL}$ characteristics}

Fig. 2 presents the TL glow curves of CLBO phosphor after applying a filter test to decide on the most suitable optical filter. Different optical filter combinations including BSL-TL (365 nm) and IRSL-TL (wideband blue (wbb), 410 and $565 \mathrm{~nm}$ ) filters were evaluated and IRSL-TL $565 \mathrm{~nm}$ filter giving the optimal TL glow curve having the highest TL intensity was chosen. Besides the TL intensity, another important point is the position and shape of the apparent peak maxima in the 
TL glow curve of the CLBO phosphor. For this reason, it has been decided that IRSL-TL $565 \mathrm{~nm}$ is also the ideal filter for further TL analysis. As seen in Fig. 2, the glow curve of CLBO sample has two TL maxima at around 70 and $200{ }^{\circ} \mathrm{C}$. As known, low temperature TL peaks, the trapping energies related to shorter lifetimes, are not resistant. These TL peaks can be erased using an appropriate thermal cleaning, namely preheating, the process performed before each TL readout to avoid the presence of an intense TL signal that may influence the shape and position of the respective peak(s) located at a higher temperature region. Thus, preheating was performed to CLBO phosphor by applying a plateau test to remove the TL signal at $70{ }^{\circ} \mathrm{C}$.

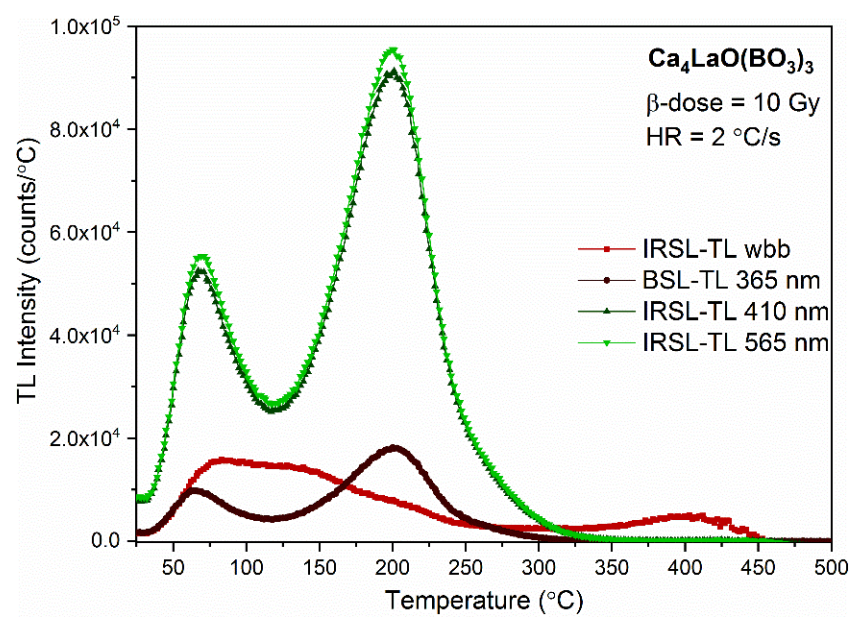

Figure 2. TL glow curves of CLBO phosphor obtained by the filter test

Preheating test was first applied to detect the $\mathrm{PH}$ temperature of the CLBO phosphor exposed to beta irradiation of $10 \mathrm{~Gy}$ before each readout. After the irradiation, the pellet sample was initially heated to a temperature $\left(T_{\text {stop }}\right)$, then rapidly cooled to RT. Then the TL glow curve was utilized using a heating rate of 2 ${ }^{\circ} \mathrm{C} / \mathrm{s}$. For this purpose, the thermal cleaning process was reiterated for all $T_{\text {stop }}$ values between 100 and 151 ${ }^{\circ} \mathrm{C}$ with $3{ }^{\circ} \mathrm{C}$ intervals. As presented in Fig. 3(a), the $\mathrm{PH}$ temperature of CLBO phosphor was selected as $125{ }^{\circ} \mathrm{C}$ connected with the plateau observed. Then, keeping the decided $\mathrm{PH}$ temperature constant, $125^{\circ} \mathrm{C}$ $\mathrm{PH}$ temperature was applied to the $10 \mathrm{~Gy}$ irradiated CLBO sample for the periods between 0 and $40 \mathrm{~s}$ before each TL measurement (Fig. 3(b)). Subsequently, $25 \mathrm{~s}$ PH duration was chosen as an appropriate time corresponding to the plateau region as well. Defined PH temperature and time $\left(125^{\circ} \mathrm{C}, 25 \mathrm{~s}\right)$ were operated for the rest of the TL analysis.

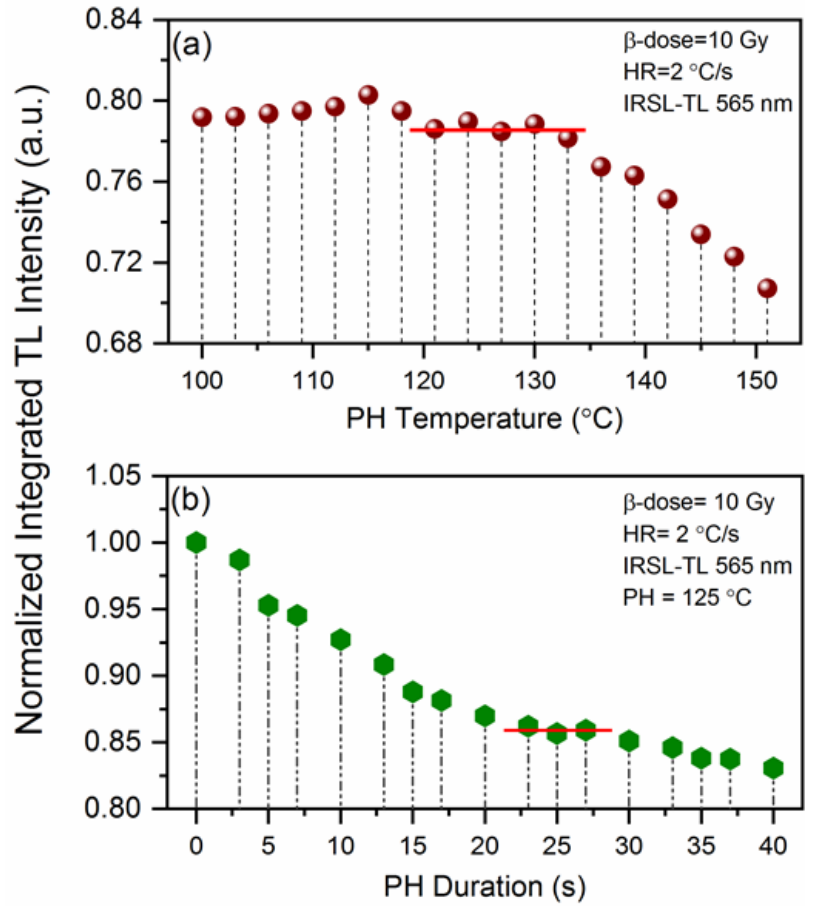

Figure 3. Normalized integrated TL intensities of CLBO phosphor vs (a) $\mathrm{PH}$ temperature and (b) $\mathrm{PH}$ time

As shown in Fig. 4, the glow curve of CLBO did not significantly change by the preheating procedure. If we draw the integral of the TL intensity versus temperature, we can get information about whether the apparent maximum at $200{ }^{\circ} \mathrm{C}$ consists of overlapped TL peaks (inset figure of Fig. 4). Hence, it has been seen that the apparent maximum actually consists of at least three peaks while the whole glow curve comprises at least four peaks where the first erased one corresponds to the low temperature peak. 


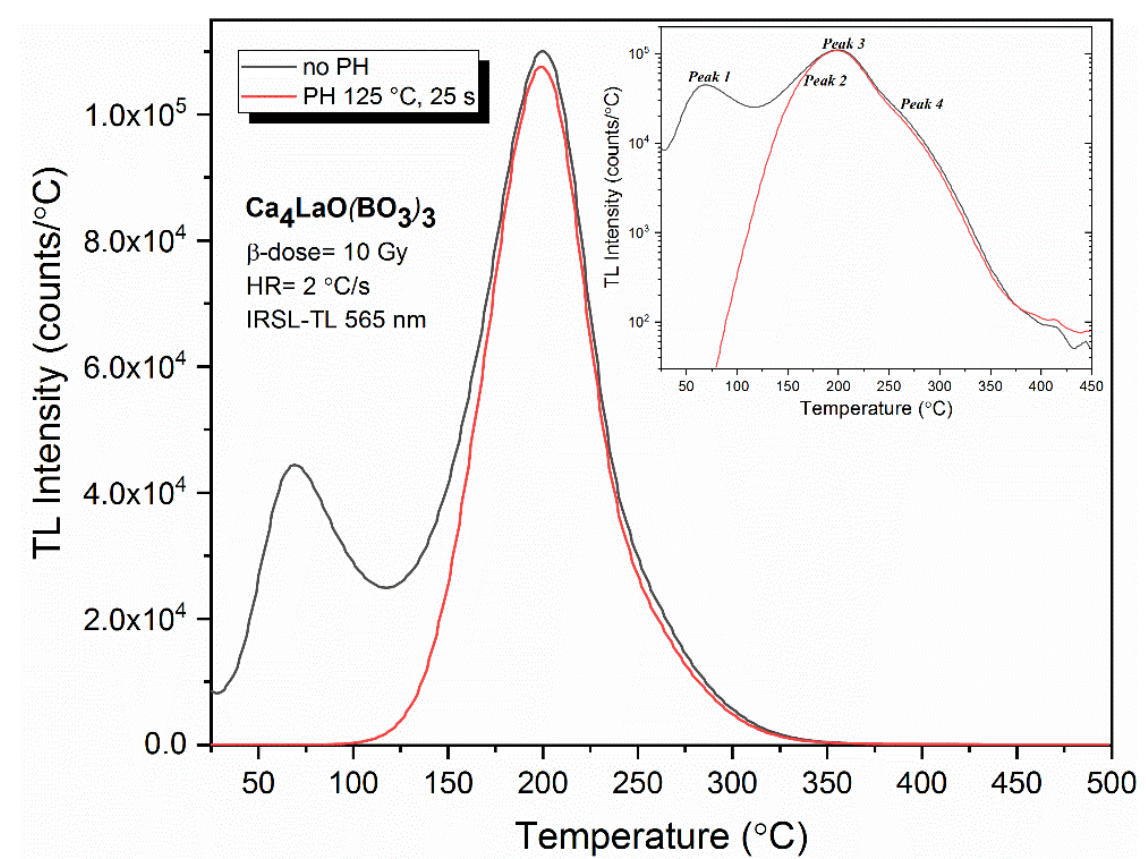

Figure 4. Preheated and non-preheated CLBO sample (inset: a logarithmic plot to evaluate overlapping TL peaks)

Fig. 5 shows the TL glow curves with changing it is clear from Fig. 5(a), the TL peak intensity exposure for the beta irradiations between $0.1-150 \mathrm{~Gy}$ and the linear behavior versus the given dose. The TL glow curves of CLBO phosphor were obtained after preheating $\left(125^{\circ} \mathrm{C}, 25 \mathrm{~s}\right)$ with a heating rate of $2{ }^{\circ} \mathrm{C} / \mathrm{s}$. TL emissions were increased with the increasing beta dose up to 150 Gy which was the highest dose that can be given since the photomultiplier tube (PMT) has gradually increases but the shape of the TL glow peak expands by the increasing dose at the same time. Besides, the TL peak position is changed and shifts slightly to lower temperature sides when the given dose increases. The change in the $T_{\mathrm{M}}$ of the glow peak is observed as $\sim 10{ }^{\circ} \mathrm{C}$ between the lowest $(0.1 \mathrm{~Gy})$ and highest (150 Gy) beta dose. reached the maximum detection limit it can detect. As

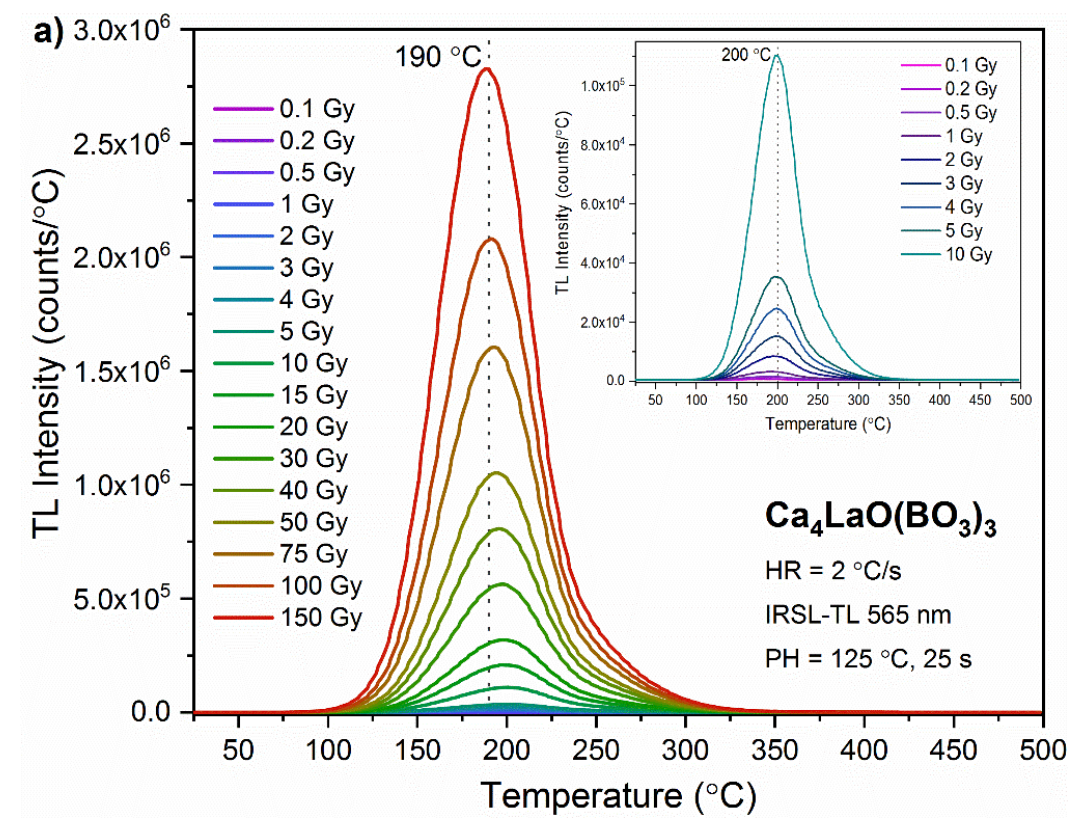




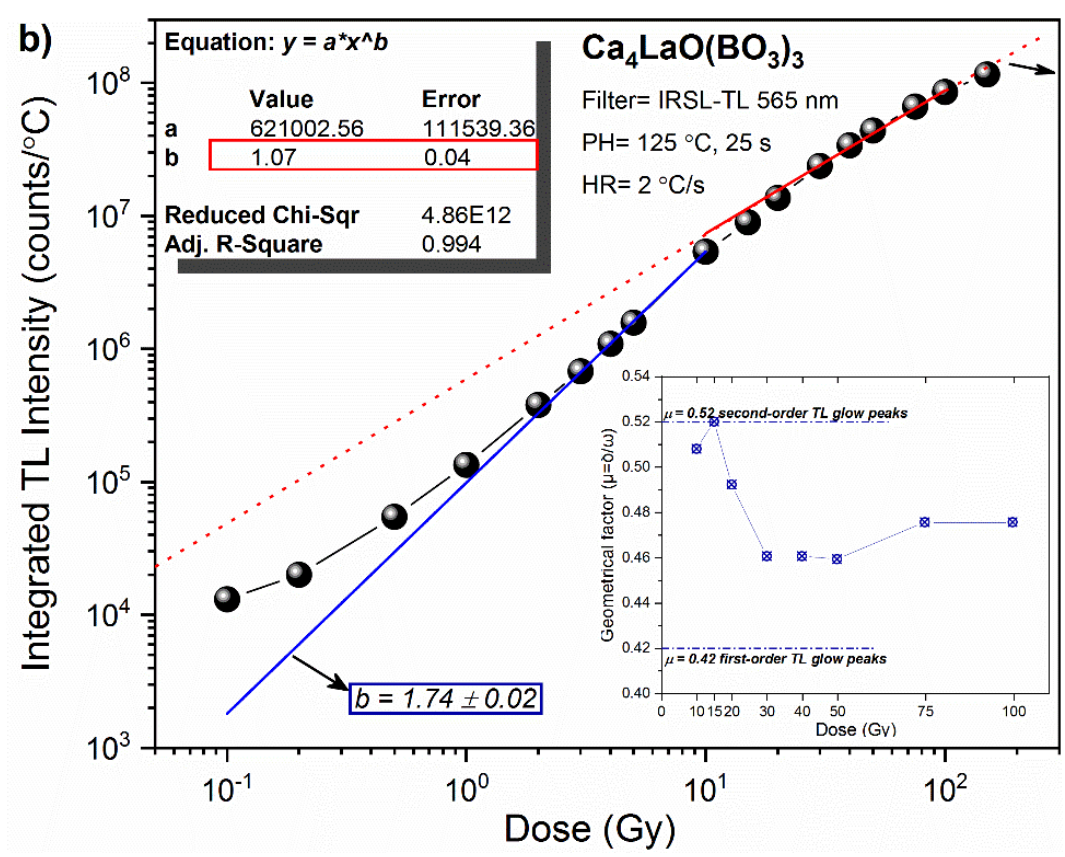

Figure 5. (a) Dose response of preheated CLBO in the range of 0.1-150 Gy (inset: 0.1-10 Gy), (b) Linearity plot (inset: symmetry factors of the glow curves obtained at the doses in the linear range

The impact of the given dose on $T_{\mathrm{M}}$ is provided by one trap one recombination (OTOR) model which is the simplest phenomenological model for TL [29]. In the OTOR model, the radiation dose is represented by the ratio $n_{0} / N$, where $n_{0}\left(\mathrm{~cm}^{-3}\right)$ is the primary concentration of filled traps at first, $N\left(\mathrm{~cm}^{-3}\right)$ is the total concentration of electron traps within the crystal. Here, the ratio describes the filling degree of the trap responsible for a TL peak. Although this model does not contain information about the kinetic order $b$, May and Partridge suggested a general order equation, and the dose is represented by the term $\left(n_{0} / N\right)^{b_{-1}}$ [30]. For general order of kinetics, when the dose increases, the $T_{\mathrm{M}}$ shifts to lower temperatures since the re-trapping decreases and the recombination increases [31].

Furthermore, the obtained results of the TL glow curves for additive dose present that CLBO sample exhibits a linear behavior (e.g. the slope is nearly 1.0, $\mathrm{R}^{2}=0.99$ ) in the range of 10-100 Gy as shown in Fig. 5(b). Superlinear behavior of the glow curve is also presented within the lower dose region between 0.1 and $10 \mathrm{~Gy}$ (in Fig. 5(b)). Although there was a decrease in the integrated intensity after $100 \mathrm{~Gy}$, it could not be determined whether it was saturated since the higher doses could not be applied. It has been observed that CLBO has a linearity at higher dose range compared to un-doped borate based phosphors evaluated previously by various researchers (especially, stated in the introduction section). Moreover, symmetry factor $\mu$ was obtained to argue the order of kinetics of the TL glow peak by taking its shape or geometrical characteristics into account. Symmetry factors correspond to 0.42 and 0.52 values for the occurrence of first and second order kinetics, individually. This method is based on the peak temperature $T_{\mathrm{M}}$, the temperature at half of the maximum intensity $\left(I_{\mathrm{M}}\right)$ of the ascending part of the peak $T_{1}$ and the descending part $T_{2}$. Thus, the symmetry factor $(\mu=\delta / \omega)$ is calculated using the ratio of the half widths at high temperature side $\left(\delta=T_{2}-T_{\mathrm{M}}\right)$ and the total one $(\omega=$ $T_{2}-T_{1}$ ) [32]. Thus, the symmetry factor $\mu$ was evaluated from the glow curves obtained by dose response analysis to evaluate the kinetic order. In Fig. 5 (b), it is also noticed that the glow curves obey the general order of kinetics. 


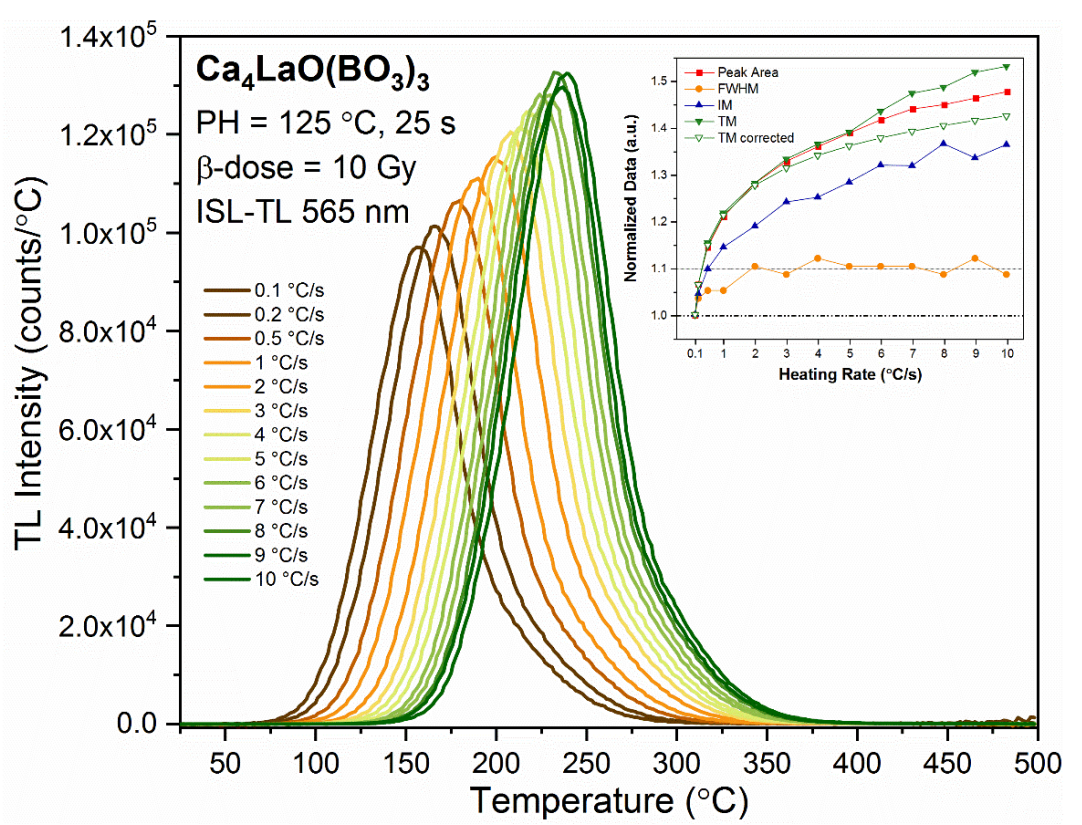

Figure 6. TL glow curves of CLBO obtained by using different heating rate values $\left(0.1-10{ }^{\circ} \mathrm{C} / \mathrm{s}\right)$ (inset: Normalized data)

In general, TL glow curves shift in the direction of the higher temperature side during the TL readout with faster heating rates [25,33]. Fig. 6 represents this outcome in the TL glow curves of CLBO phosphor using various heating rates. The inset figure contains the parameters obtained by the glow curves for various heating rates and each parameters were normalized according to the first data achieved by using the glow curve with the the lowest heating rate $\left(0.1^{\circ} \mathrm{C} / \mathrm{s}\right)$. A slight shift is expected case since the traps within the band gap of the phosphor are emptied in a shorter time period at the faster heating rates and therefore, $T_{\mathrm{M}}$ increases. In addition, full width half maximum (FWHM) increases while maximum intensity $\left(I_{\mathrm{M}}\right)$ decreases according to the TL theory. However, the integrated peak intensity must be constant [34]. As seen in both Fig. 6 and the inset figure, both the peak integral and $I_{\mathrm{M}}$ increases with the increasing heating rate which is defined as an anomalous heating rate phenomenon contrary to the expected situation explained by the OTOR model. Pagonis et al. [3] reported this anomalous heating rate or "antiquenching" effect by using the Mandowski model, namely semi-localized transitions (SLT), by introduced an accessional non-radiative transition through the recombination center from the directly excited state. The stimulated electrons by heating from the trap to an excited state are thermally delivered into the conduction band where they can be captured or reassembled with holes in the recombination centers. In the first scenario, this recombination mechanism is supposed to yield a TL signal. An electron in the excited state can directly recombine with a hole in the recombination center without a radiative transition in either way. The relative ratio of radiative against nonradiative transition possibilities decreases when the heating rate decreases and vise versa. The two-stage process of stimulation of the charge carriers from the traps is the reason for such behavior. The whole amount of localized transitions is comparative to the entire time exhausted in an excited state by the trapped electrons. This time decreases resulting from the higher probability rates of thermally excited transitions into the conduction band at higher heating rates. Therefore, the physical base of the anomalous effect is a rivalry among the radiative and non-radiative mechanisms. This rivalry for current charges between the two mechanisms creates the integrated TL intensity to rise, whereas the comparable non-radiative one has to decrease with the identical quantity due to the charge conservation. Thus, the increase in the integrated TL intensity corresponds to the rise in the probability of radiative transitions over that of the non-radiative ones [3-7].

Moreover, $T_{\mathrm{M}}$ and FWHM values of the glow curve show an increasing tendency. If we look at the inset figure of Fig. 6, it is seen that two normalized $T_{\mathrm{M}}$ values are presented. This is due to the correction of $T_{\mathrm{M}}$ values for each heating rate value as a result of the temperature lag effect. The temperature of the heating element changes from the temperature of the sample during the TL readout and non-ideal thermal contact, namely temperature lag, may affect the calculated trapping parameters of the TL glow peak [35]. By accepting that the lowest two heating rates $(0.1$ and 0.2 ${ }^{\circ} \mathrm{C} / \mathrm{s}$ ) are not affected by the temperature lag, Eq. 2 is 
used to correct $T_{\mathrm{M}}$ values for the glow curves obtained with the higher heating rates.

$$
T_{M j}=T_{M i}-c \ln \left(\frac{\beta_{i}}{\beta_{j}}\right)
$$

$T_{\mathrm{Mj}}$ and $T_{\mathrm{Mi}}$ represent the maximum temperatures for $\beta_{\mathrm{j}}$ and $\beta_{\mathrm{i}}$ heating rates, and $c$ is a constant quantity that is computed utilizing the two lowest heating rates. Therefore, normalized values of both $T_{\mathrm{M}}$ data,

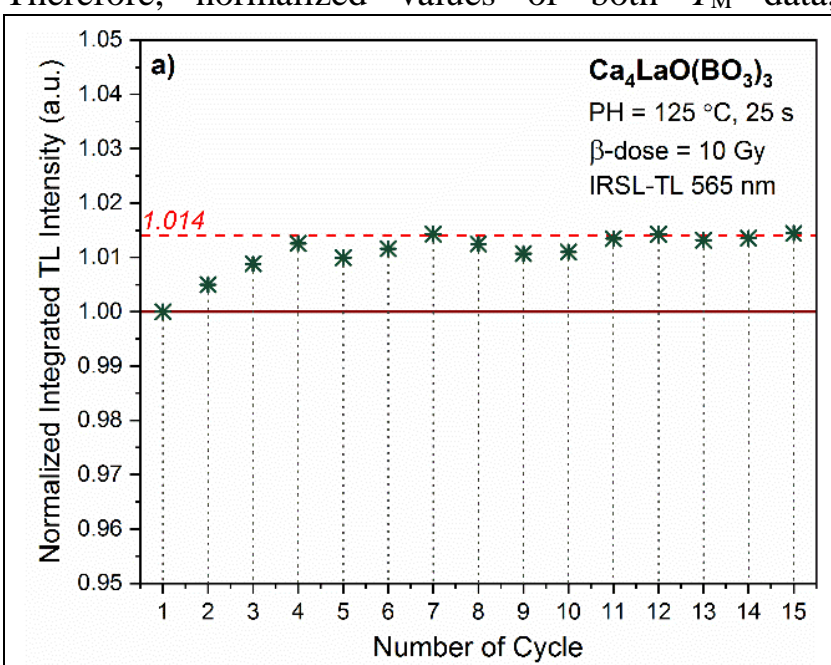

Figure 7. (a) Reusability plot achieved by $15 \mathrm{TL}$ readout cycle and (b) storage time measurements up to a week

In dosimetric applications, reusability and storage time measurements are of great significance to search the usage of a prepared TL material. Since it is desirable that the material remains stable so as to give the same TL signal for each repetitive reading and during the elapsed time. As shown in Fig. 7(a), the obtained standard deviation of the integrated TL intensity is approximately $4 \%$ which is in the tolerance ranges acceptable for dosimetric materials stated as less than $5 \%$ [36]. Storage time characteristics of beta irradiated CLBO was checked to evaluate short time storage during a week in the dark at RT after 10 Gy beta exposure. For the visible peak maxima at $\sim 200{ }^{\circ} \mathrm{C}$, the fading rate was nearly $5 \%$ after a week. Instead of fading, a fluctuation was observed within the $5 \%$ confidence interval during the stored time period. A growth of peak height to $5 \%$ over ten minutes and another increase to 3-4 \% after three hours were observed however a forecastable fading was obtained experimentally obtained (uncorrected) and corrected by utilizing temperature lag equation (Eq. 5) are presented in the inset figure of Fig. 6. After the temperature lag correction, it was seen that the increase in $T_{\mathrm{M}}$ is $10 \%$ less for the highest heating rate applied $\left(10^{\circ} \mathrm{C} / \mathrm{s}\right)$ as the heating rate increased.

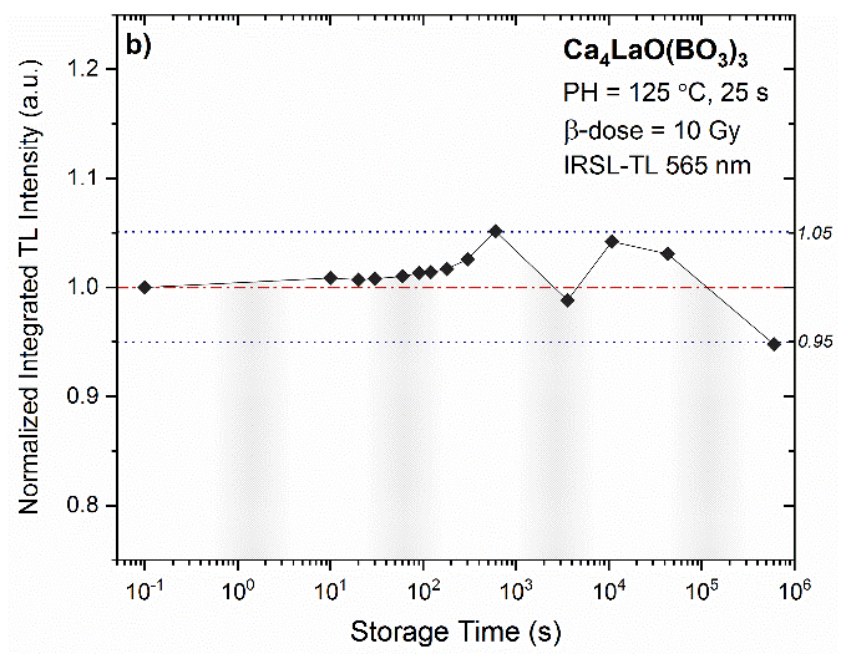

when the storage time was extended and a sort of recovery was observed after $3 \mathrm{~h}$ storage time (Fig. 7(b)). An initial increase of the integrated TL intensity may have possibly occurred by a tunneling transfer among the traps as a non-thermal process due to the existence of intense spatial correlations between the traps and recombination centers [37]. Similar abnormal results were also highlighted in the literature by the various researchers for the different TL materials [3839] as well.

\subsection{TL kinetics}

To estimate the kinetic parameters of $\mathrm{Ca}_{4} \mathrm{LaO}\left(\mathrm{BO}_{3}\right)_{3}$ phosphor, $T_{\mathrm{M}}-T_{\text {stop }}$, and IR methods have been operated on the strength of the presume that the TL glow curve consists of an isolated TL peak maximum. Further, the GCD method was performed to evaluate whether the experimental glow curve has overlapped TL peaks. 


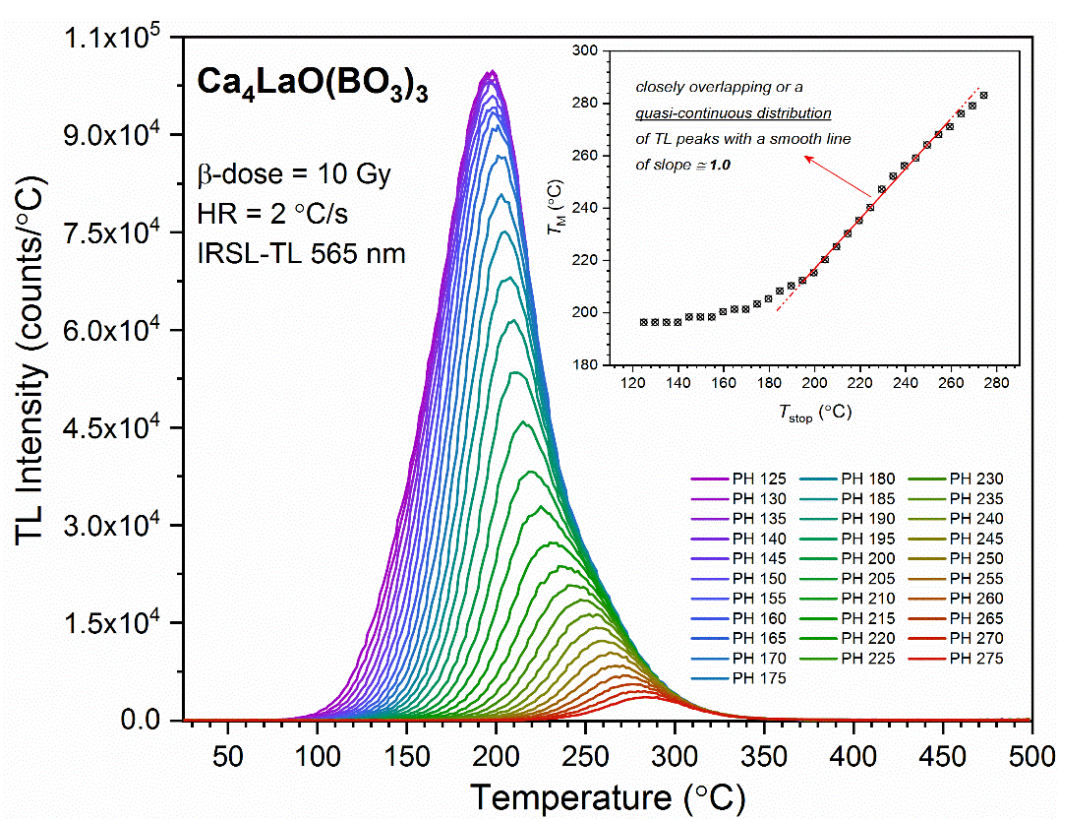

Figure 8. TL glow curves of CLBO sample obtained after preheating to various $T_{\text {stop }}$ values (inset: $T_{\mathrm{M}}-T_{\text {stop }}$ dependency)

At first, 10 Gy beta dose was applied to the phosphor and then, it was heated up to a stopping temperature $\left(T_{\text {stop }}\right)$. Afterward, the TL glow curve was obtained with a constant heating rate of $2{ }^{\circ} \mathrm{C} / \mathrm{s}$. This cycle was repeated under the same conditions using $T_{\text {stop }}$ values between 125 and $275^{\circ} \mathrm{C}$ with $5{ }^{\circ} \mathrm{C}$ intervals (Fig. 8). $T_{\mathrm{M}}-T_{\text {stop }}$ method is generally used to estimate the numbers and possible locations of overlapped TL peaks. Therefore, $T_{\mathrm{M}}$ versus $T_{\text {stop }}$ plot was achieved for the preheated TL glow curve data of CLBO phosphor and presented in the inset figure of Fig. 8. If a TL glow curve contains various and clearly separated first order TL peaks, $T_{\mathrm{M}}-T_{\text {stop }}$ curve presents a characteristic "staircase" structure having individual flat regions. Considering a glow curve consisting of more closely overlapping peaks, the curve turns into a smoother shape and the $T_{\mathrm{M}}$ representing the flat regions can exclusively be utilized as an indicator of the locations of each individual peak. When the TL peaks overlap, even more, the case is disposed to the presence of a quasi-continuous distribution of the TL peaks (in other words, trapping centers). $T_{\mathrm{M}}-T_{\text {stop }}$ curve will transfer to a continuous line with a slope $\mathrm{f} 1.0$ at this stage. The limit of detection of flat regions within the $T_{\mathrm{M}}-T_{\text {stop }}$ curve gives a measure of the resolution of the technique [24]. According to the inset figure of Fig. 8, it is seen that the single TL maximum, obtained after a $\mathrm{PH}\left(125^{\circ} \mathrm{C}, 25 \mathrm{~s}\right)$ procedure, consists of several closely located overlapping TL peaks rather than a single trapping level. Therefore, none of the overlapped TL peaks are subject to first order kinetics.
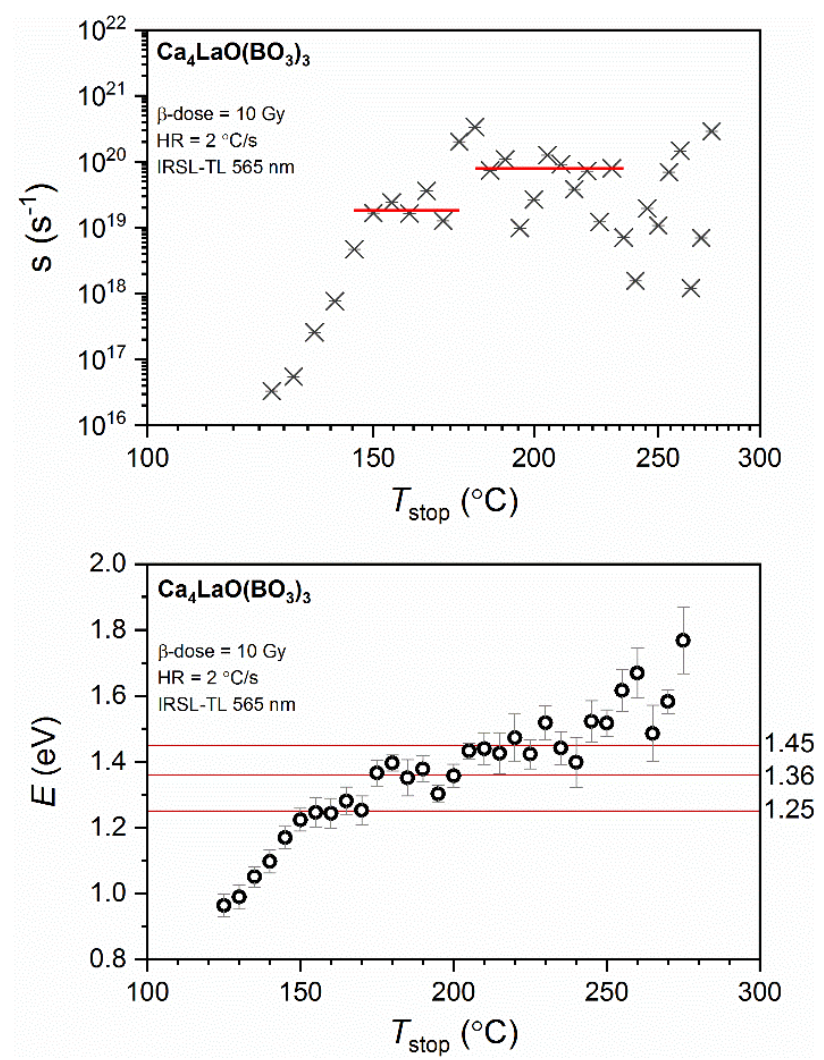

Figure 9. Trap parameters of $s$ (top), $E$ (bottom) against to $T_{\text {stop }}$ for CLBO phosphor.

To examine the $E$ and $s$ values of CLBO phosphor by using $T_{\mathrm{M}}-T_{\text {stop }}$ analysis, the IR method which is a quite reliable technique to obtain trap parameters was also utilized. Therefore, this method was operated on to each glow curve obtained after the $T_{\mathrm{M}}-T_{\text {stop }}$ analysis. Mean activation energies and frequency factors of these energy levels were computed by utilizing the initial rise method to each TL peak at a different $T_{\text {stop. }}$. 
Calculated $E$ and $s$ values were plotted against the applied $T_{\text {stop }}$ and presented in Fig. 9. As seen in Fig. 9, a variation of the activation energy and frequency factor present at least three possible trap levels of preheated CLBO phosphor. Supporting the result of the inset figure of Fig. 8, $E$ and $s$ values were obtained from $150{ }^{\circ} \mathrm{C}$ towards higher temperatures for the closely positioned TL peaks. Therefore, the results reveal that the preheated CLBO sample has a continuous trap distribution with activation energies of $1.25,1.36$, and $1.45 \mathrm{eV}$. Furthermore, frequency factors were found within the range of $10^{19}$ and $10^{20} \mathrm{~s}^{-1}$. Since the transport phase includes several nonradiative routes of electron loss, the higher frequency factors pointed out that the trap and luminescence sites are closely linked [40]. Further, GCD analysis in Fig. 10 suggests that there are a variety of closely positioned component bands that all contribute to the TL glow peak.
Moreover, trap parameters $E$ and $s$ of the TL peak maximum at $200{ }^{\circ} \mathrm{C}$ were calculated by the IR method using the glow curves obtained from various heating rate and additive dose, respectively. Considering the fact that the use of the IR method may be more dependable than various heating rate (VHR) method to derive $E$, particularly for phosphors where there is a strong competition between radiative and nonradiative pathways stated by Pagonis et al. [3], the VHR method was not preferred for the calculation of trap parameters of the TL peak maximum in this study. Certain TL glow curves presented in Fig. 5(a) and 6 have been evaluated for this purpose. Therefore, the trap parameters were calculated by plotting the temperature-dependent graphs of the initial rise parts of the glow curves obtained using the heating rates between 0.1 and $5{ }^{\circ} \mathrm{C} / \mathrm{s}$ (beta dose is fixed at $10 \mathrm{~Gy}$ ) and doses between 10-100 Gy (a linear heating rate is fixed at $2{ }^{\circ} \mathrm{C} / \mathrm{s}$ ) in the linear dose range. Obtained parameters of $E$ and $s$ are shown in Table 1 .

Table 1. Estimated kinetic parameters using IR method applied to the heating rate (HR) and dose response glow curves

\begin{tabular}{|c|c|c||c|c|c|}
\hline HR $\left({ }^{\circ} \mathbf{C} / \mathbf{s}\right)$ & $\boldsymbol{E}(\mathbf{e V})$ & $\boldsymbol{s}\left(\mathbf{s}^{\mathbf{- 1}}\right)$ & Dose $(\mathbf{G y})$ & $\boldsymbol{E}(\mathbf{e V})$ & $\boldsymbol{s}\left(\mathbf{s}^{\mathbf{- 1}}\right)$ \\
\hline 0.1 & $1.035 \pm 0.046$ & $1.60 \times 10^{18}$ & 10 & $1.210 \pm 0.035$ & $1.50 \times 10^{19}$ \\
\hline 0.2 & $1.026 \pm 0.030$ & $6.82 \times 10^{17}$ & 15 & $1.187 \pm 0.028$ & $1.47 \times 10^{19}$ \\
\hline 0.5 & $1.067 \pm 0.044$ & $1.08 \times 10^{18}$ & 20 & $1.162 \pm 0.035$ & $1.13 \times 10^{19}$ \\
\hline 1 & $1.152 \pm 0.025$ & $6.68 \times 10^{18}$ & 30 & $1.184 \pm 0.032$ & $3.93 \times 10^{19}$ \\
\hline 2 & $1.171 \pm 0.036$ & $5.05 \times 10^{18}$ & 40 & $1.164 \pm 0.032$ & $3.38 \times 10^{19}$ \\
\hline 3 & $1.237 \pm 0.032$ & $1.84 \times 10^{19}$ & 50 & $1.170 \pm 0.032$ & $5.46 \times 10^{19}$ \\
\hline 4 & $1.182 \pm 0.031$ & $2.52 \times 10^{18}$ & 75 & $1.173 \pm 0.036$ & $1.00 \times 10^{20}$ \\
\hline 5 & $1.275 \pm 0.047$ & $2.14 \times 10^{19}$ & 100 & $1.178 \pm 0.037$ & $1.62 \times 10^{20}$ \\
\hline
\end{tabular}

According to the results presented in Table $1, E$ value of the TL peak maximum does not importantly vary with the increasing dose as a result of being doseindependent. However, a slight increase in $E$ values from 1.04 to $1.28 \mathrm{eV}$ is seen with the increasing heating rate. As seen in Table 1, the energy values obtained by the IR method using both ways are in concordance with each other. However, effective activation energies presented in Table 1 differ from the acquired IR results using $T_{\mathrm{M}}-T_{\text {stop }}$ analysis. This indicates that the TL glow curve of a preheated CLBO phosphor is a complex curve consisting of overlapped peaks, else the findings obtained using the three ways should match. In addition, similar and high frequency factors were found as also presented in those observed by $T_{\mathrm{M}}-T_{\text {stop }}$ analysis. Therefore, results supporting the interpretation that the trap and luminescence centers are located very close to each other have been obtained.

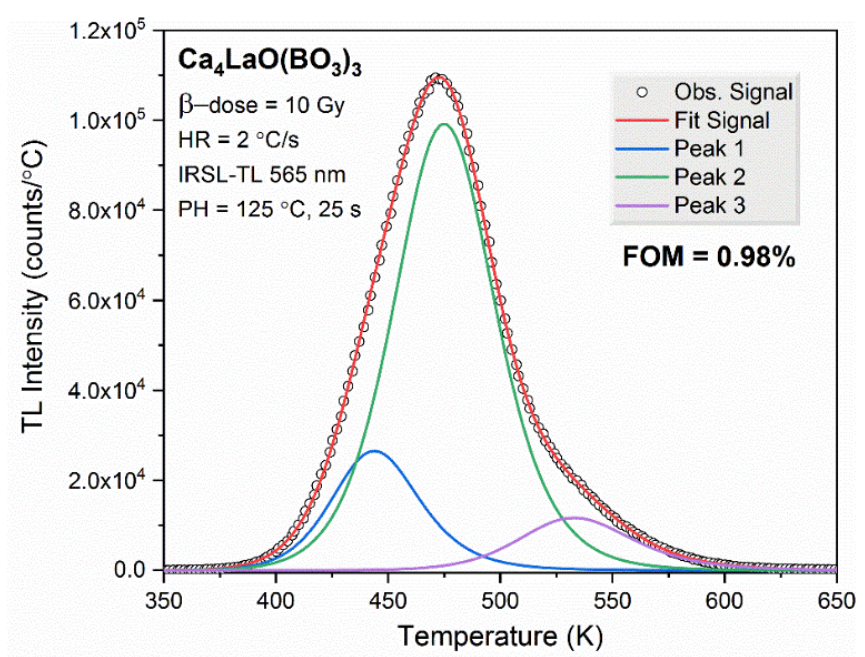

Figure 10. Deconvolution of the TL glow curve of preheated CLBO phosphor 
The glow curve deconvolution (GCD) method is used to decompose the TL glow peak and achieve the kinetic parameters of the preheated CLBO phosphor. GCD method was operated using the general order kinetics in connection with the dose response evaluations of preheated CLBO phosphor. GCD plot and decomposed TL glow peaks in Fig. 10 presents that the experimental TL glow curve of the sample after $10 \mathrm{~Gy}$ beta exposure at a heating rate of $2{ }^{\circ} \mathrm{C} / \mathrm{s}$ was decently fitted with three TL peaks. As presented in the figure, TL emission begins to increase after $350 \mathrm{~K}$, arrives at maximum TL intensity at $474 \mathrm{~K}$, and depletes entirely around $650 \mathrm{~K}$. Thus, the remaining part of the recorded data from the total TL spectrum between 300 and $770 \mathrm{~K}$ is not included in the figure (Fig. 10). It is seen that the deconvolution results of CLBO phosphor give a reliable evaluation of the trap parameters with a FOM value of $0.98 \%$. In addition, lifetimes $(\tau)$ of the TL glow peaks are an important argument to investigate the TL materials about their effectiveness in either dosimetry or dating Eq. 3 was utilized to calculate the lifetimes of the decomposed TL peaks.

$$
\tau=s^{-1} \exp \left(\frac{E}{k T}\right)
$$

$T$ is the storage temperature which was employed to be $298 \mathrm{~K}$ for the computation. All kinetic parameters of the deconvoluted TL peaks are shown in Table 2.

Table 2. Kinetic parameters of the deconvoluted TL glow curves of $\mathrm{Ca}_{4} \mathrm{LaO}\left(\mathrm{BO}_{3}\right)_{3}$ using R-studio $(\mathrm{FOM}=0.98 \%)$

\begin{tabular}{|l||c|c|c|c|c|}
\hline \multicolumn{1}{|c||}{} & \multicolumn{5}{c|}{$\mathrm{Ca}_{4} \mathrm{LaO}_{\left(\mathbf{B O}_{3}\right)_{3}}$} \\
\cline { 2 - 6 } & \hline $\boldsymbol{E}(\mathbf{e V})$ & $\mathbf{s}\left(\mathbf{s}^{-1}\right)$ & $\mathbf{b}$ & $\boldsymbol{T}_{\mathbf{M}}\left({ }^{\circ} \mathrm{C}\right)$ & $\sigma($ year $)$ \\
\hline Peak 1 & 1.233 & $1.40 \times 10^{13}$ & 2 & 171 & 1.60 \\
\hline Peak 2 & 1.146 & $1.61 \times 10^{11}$ & 1.79 & 201 & 4.54 \\
\hline Peak 3 & 1.375 & $1.07 \times 10^{12}$ & 2 & 259 & 5110.54 \\
\hline
\end{tabular}

According to the results, when peak 1 at $171{ }^{\circ} \mathrm{C}$ and 3 at $259^{\circ} \mathrm{C}$ are of second order of kinetics, peak 2 at 201 ${ }^{\circ} \mathrm{C}$ is of general order kinetics. GCD results represented similar results to those found by the IR method using $T_{\mathrm{M}}-T_{\text {stop }}$ analysis since the number of decomposed TL peaks and their maximum peak temperature are in good agreement. In addition, the average $E$ values are also in concordance with the IR findings obtained by the results of $T_{\mathrm{M}}-T_{\text {stop }}$ analysis. The frequency factors of the continuously distributed overlapped peaks were found as $1.40 \times 10^{13}, 1.61 \mathrm{x}$ $10^{11}$, and $1.07 \times 10^{12} \mathrm{~s}^{-1}$, respectively. Moreover, the lifetimes of the TL peaks were obtained long enough for dosimetry applications.

\section{Conclusion}

$\mathrm{Ca}_{4} \mathrm{LaO}\left(\mathrm{BO}_{3}\right)_{3}$ phosphor was produced by a solid state synthesis. XRD was conducted to evaluate the crystal structure and it was reported that the pattern of synthesized phosphor is in good agreement and matches well with the reference card. After applying adequate preheating, additive beta dose and various heating rates were applied to examine the behaviors of the TL glow curves. Consequently, $200{ }^{\circ} \mathrm{C}$ TL peak maximum presented a linear dose response behavior within 10 and $100 \mathrm{~Gy}$. Anomalous behavior of the TL peak maximum of preheated $\mathrm{Ca}_{4} \mathrm{LaO}\left(\mathrm{BO}_{3}\right)_{3}$ phosphor has been reported with increasing heating rate between 0.1 and $10{ }^{\circ} \mathrm{C} / \mathrm{s}$. This anti-quenching behavior may be interpreted by a semi-localized transition model presuming that radiative and non-radiative transitions compete. In addition, the material was reported as a reusable phosphor for dosimetric applications within the $5 \%$ confidence interval. Storage time for a short period of up to a week was also found with an excellent $5 \%$ standard deviation. Trapping parameters and the kinetic analysis of $\mathrm{Ca}_{4} \mathrm{LaO}\left(\mathrm{BO}_{3}\right)_{3}$ phosphor were evaluated by using $T_{\mathrm{M}}-T_{\text {stop }}$ and IR methods and the results were compared with deconvolved glow curve data, which was collected using tgcd: an $\mathrm{R}$ package software. The obtained results by GCD were found compatible with the other methods representing a continuous trap distribution. According to the findings, the main dosimetric peak of $\mathrm{Ca} 4 \mathrm{LaO}\left(\mathrm{BO}_{3}\right)_{3}$ follows the general order kinetics, as supported by dose response plot. Furthermore, the lifetimes of the decomposed TL peaks have been found to be long enough. The findings of this study present that the $\mathrm{Ca}_{4} \mathrm{LaO}\left(\mathrm{BO}_{3}\right)_{3}$ phosphor may be a good candidate to be used in high dose monitoring for dosimetric applications considering its high effective atomic number, $\mathrm{Z}_{\mathrm{eff}} \approx 36.4$, (tissue equivalence is not an issue) and the linear dose range. However, further investigations are required such as higher dose effect, long-term storage time measurements and applications of different radiation sources.

\section{Acknowledgment}

The author would like to thank Assoc. Prof. Dr. Y. Z. Halefoğlu (Çukurova University) for the valuable support on the phosphor synthesis and A. Yücel (Inonu University) for the substantial evaluations on the XRD results. The author would also appreciate Prof. Dr. M. Topaksu and Assoc. Prof. Dr. S. Akça Özalp for the precious discussions on the TL results. 


\section{Conflicts of interest}

The author declares that she has no known competing financial interests or personal relationships that could have appeared to influence the work reported in this paper.

\section{References}

[1] Chen R. and Pagonis V., The role of simulations in the study of thermoluminescence (TL), Radiat. Meas, 71 (2014) 8-14.

[2] Dogan T., Thermluminescence properties of quartize rock after $\beta$-irradiation, Cumhuriyet Sci. J., 39-4 (2018) 1136-1143.

[3] Pagonis V., Blohm L., Brengle M., Mayonado G., Woglam P., Anomalous heating rate effect in thermoluminescence intensity using a simplified semi-localized transition (SLT) model, Radiat. Meas., 51 (2013) 40-47.

[4] Mandowski A., Semi-localized transitions model for thermoluminescence, J. Phys. D: Appl. Phys. 38 (2005) 17-21.

[5] Mandowski A., Topology-dependent thermoluminescence kinetics, Radiat. Prot. Dosim,. 119 (2006) 23-28.

[6] Mandowski A., Semi-localized transitions modelGeneral formulation and classical limits, Radiat. Meas,. 43 (2008) 199-202.

[7] Mandowski A., Bos A.J.J., Explanation of anomalous heating rate dependence of thermoluminescence in $\mathrm{YPO}_{4}: \mathrm{Ce}^{3+}, \mathrm{Sm}^{3+}$ based on the semi-localized transition (SLT) model, Radiat. Meas., 46 (2011) 1376-1379.

[8] Kitis G., Furreta C., Prokic M., Prokic V., Kinetic parameters of some tissue equivalent thermoluminescence materials, J. Phys. D Appl. Phys. 33 (2000) 1252-1262.

[9] Peng M., Wondraczek L., Orange-to-red emission from $\mathrm{Bi}^{2+}$ and alkaline earth codoped strontium borate phosphors for white light emitting diodes, J. Am. Ceram. Soc. 93 (2010) 1437-1442.

[10] Kelemen A., Mesterházy D., Ignatovych M., Holovey V., Thermoluminescence characterization of newly developed $\mathrm{Cu}$-doped lithium tetraborate materials, Radiat. Phys. Chem., 81 (2012) 1533-1535.

[11] Furetta C., Prokic M., Salamon R., Prokic V., Kitis G., Dosimetric characteristics of tissue equivalent thermoluminescent solid TL detectors based on lithium borate, Nucl. Instrum. Meth. A 456 (2001) 411-417.

[12] Kafadar V.E., Yildirim R.G., Zebari H., Zebari D., Investigation of thermoluminescence characteristics of $\mathrm{Li}_{2} \mathrm{~B}_{4} \mathrm{O}_{7}: \mathrm{Mn}$ (TLD-800), Thermochim. Acta, 575 (2014) 300-304.

[13] Oglakci M., Akça S., Halefoglu Y.Z., Dogan T., Ayvacikli M., Karabulut Y., Topaksu M., Can N., Characterization and thermoluminescence behavior of beta irradiated $\mathrm{NaBaBO}_{3}$ phosphor synthesized by combustion method, Ceram. Int., 45 (2019) 7011-7017.

[14] Chen Z., Chen X., Huang S., Pan Y., A novel tunable green-to-red emitting phosphor $\mathrm{Ca}_{4} \mathrm{Lao}\left(\mathrm{BO}_{3}\right)_{3}: \mathrm{Tb}^{3+}, \mathrm{Eu}^{3+}$ via energy transfer with high quantum yield, Ceram. Int., 42 (2016) 13476-13484.

[15] Chen Z., Pan Y., Xi L., Pang R., Huang S., Liu G., Tunable Yellow-Red Photoluminescence and Persistent Afterglow in Phosphors $\mathrm{Ca}_{4} \mathrm{LaO}\left(\mathrm{BO}_{3}\right)_{3}: \mathrm{Eu}^{3+}$ and $\mathrm{Ca}_{4} \mathrm{EuO}\left(\mathrm{BO}_{3}\right)_{3}$, Inorg. Chem., 55 (2016) 11249-11257.

[16] Wu X., Yin B., Ren Q., Zheng J., Ren Y., Hai O., Structure, luminescence, properties and energy transfer of $\mathrm{Dy}^{3+}$ and $\mathrm{Eu}^{3+}$ codoped $\mathrm{Ca}_{4} \mathrm{LaO}\left(\mathrm{BO}_{3}\right)_{3}$ phosphor, J. Alloys Compd. 822 (2020) 153562.

[17] Adams J.J., Ebbers C.A., Schaffers K.I., Payne S.A., Nonlinear optical properties of $\mathrm{LaCa}_{4} \mathrm{O}\left(\mathrm{BO}_{3}\right)_{3}$, Opt. Lett. 26 (2001) 217-219.

[18] Jiang H.D., Li D.W., Zhang K.Q., Liu H., Wang J.Y., Optical and thermal properties of nonlinear optical crystal $\mathrm{LaCa}_{4} \mathrm{O}\left(\mathrm{BO}_{3}\right)_{3}$, Chem. Phys. Lett. 372 (2003) 788-793.

[19] Nelson A.J., van Buuren T., Willey T.M., Bostedt C., Adams J.J., Schaffers K.I., Terminello L., Callcott T.A., Electronic structure of lanthanum calcium oxoborate $\mathrm{LaCa}_{4} \mathrm{O}\left(\mathrm{BO}_{3}\right)_{3}$, J. Electron Spectrosc. Relat. Phenom, 137-140 (2004) 541546.

[20] Kelly N.D. and Dutton S.E., Magnetic Properties of Quasi-One-Dimensional Lanthanide Calcium Oxyborates $\mathrm{Ca}_{4} \mathrm{LnO}\left(\mathrm{BO}_{3}\right)_{3}$, Inorg. Chem., 59 (2020) 9188-9195.

[21] Lu Y. and Wang G.F., Growth and spectroscopic properties of $\mathrm{Nd}^{3+}: \mathrm{LaCa}_{4} \mathrm{O}\left(\mathrm{BO}_{3}\right)_{3}$ crystals, $J$. Cryst. Growth, 253 (2003) 270-273.

[22] Lu Y., Hu Z.S., Lin Z.B., Wang G.F., Growth and spectroscopic properties of $\mathrm{Er}^{3+} \mathrm{Yb}^{3+}$ : $\mathrm{LaCa}_{4} \mathrm{O}\left(\mathrm{BO}_{3}\right)_{3}$ crystals, J. Cryst. Growth, 249 (2003) 159-162. 
[23] Christoph R., Robert M., Margitta H., Jens G., Anke S., Horst S., Growth and structure of $\mathrm{Ca}_{4} \mathrm{La}\left[\mathrm{O}\left(\mathrm{BO}_{3}\right)_{3}\right]$, J. Cryst. Growth, 320 (2011) 90-94.

[24] McKeever S.W.S., On the analysis of complex thermoluminescence glow-curves resolution into individual peaks, Phys. Status Solidi, 62 (1980) 331-340.

[25] Chen R. and Kirsh Y., The Analysis of Thermally Stimulated Processes, Oxford: Pergamon Press, , (1981).

[26] Balian H.G., Eddy N.W., Figure of Merit (FOM), an improved Criterion over the normalised Chisquared Test for assessing Goodness-of-fit of Gamma Ray Spectra Peaks, Nucl. Instrum. Methods, 145 (1977) 389-395.

[27] Peng J., Dong Z.B., Han F.Q., Tgcd: an R package for analyzing thermoluminescence glow curves, SoftwareX, 5 (2016) 112-120.

[28] Fan T.Y. and Kokta M.R., End-Pumped Nd:LaF and $\mathrm{Nd}: \mathrm{LaMgA}_{11} \mathrm{O}_{19}$ Lasers, IEEE J. Quantum Electron, 25 (1989) 1845-1849.

[29] Halperin A. and Braner A.A., Evaluation of Thermal Activation Energies from Glow Curves, Phys. Rev., 117 (1960) 408-415.

[30] May C.E. and Partridge J.A., Thermoluminescent Kinetics of Alpha-Irradiated Alkali Halides, $J$. Chem. Phys., 40 (1964) 1401-1409.

[31] Kitis G., Mouza E., Polymeris G.S., The shift of the thermoluminescence peak maximum temperature versus heating rate, trap filling and trap emptying: Predictions, experimental verification and comparison, Physica B Condens. Matter., 577 (2020) 411754.

[32] Pagonis V., Kitis G., Furetta C., Numerical and Practical Exercises in Thermoluminescence. USA:Springer, (2006).

[33] Bos A., High sensitivity thermoluminescence dosimetry, Nucl. Instrum. Methods Phys. Res., B 184 (2001) 3-28.

[34] Kitis G., Spiropulu M., Papadopoulos J., Charalambous S., Heating rate effects on the TL glow-peaks of three thermoluminescent phosphors, Nucl. Instrum. Meth. Phys. Resear., 73 (1993) 367-372.

[35] Kitis G., Tuyn J.W.N., A Simple Method to Correct for Temperature Lag in TL Glow-Curve Measurements, J. Phys.D: Appl. Phys., 31 (1998) 2065-2073.
[36] Furetta C. Handbook of Thermoluminescence., Singapore: Word Scientific, (2003).

[37] Pagonis V., Truong P., Thermoluminescence due to tunneling in nanodosimetric materials: A Monte Carlo study, Physica B: Condens. Matter., 531 (2018) 171-179.

[38] Annalakshmi O., Jose M.T., Amarendra G., Dosimetric characteristics of manganese doped lithium tetraborate - an improved TL phosphor, Radiat. Meas., 46 (2011) 669-675.

[39] Furetta C., Pellegrini R., Some dosimetric properties of $\mathrm{Li}_{2} \mathrm{~B}_{4} \mathrm{O}_{7}: \mathrm{Mn}$ (TLD-800), Radiat. Eff. Defect. S., 58 (1-2) (1981) 17-23.

[40] Townsend P.D. Taylor G., Wintersgill M.C., A model for the activation Energies observed in TL of TLD 100, Rad. Effects, 41 (1979) 11-16. 